\title{
TREATMENT OF BILIARY INFECTIONS WITH AMPICILLIN
}

\author{
W. ZYLKA, \\ Cologne, Germany.
}

EXPERIMENTAL evaluation of ampicillin has proved that in animals this drug behaves like penicillin $G$ in being rapidly excreted in high concentrations in the bile after oral, intramuscular and intravenous administration (Table I). The ratio of bile to blood (or serum) concentration varies with the species of animal, route of administration, dose, time and technique of sampling. However these results, and the few observations in man, suggest that the administration of ampicillin to patients with inflammatory diseases of the biliary tract and gallbladder should result in biliary levels above the M.I.C. for micro-organisms likely to cause infections of this system (e.g. streptococci, Strept. faccalis, Esch. coli, various salmonellæ, etc.).

Since the organism responsible for biliary infection is frequently not isolated, tests to determine the M.I.C. may not be available. Therefore the results of treating biliary infection with ampicillin were judged by clinical observations and indirect laboratory data.

\section{Present Series}

Nineteen patients with biliary disorders (six males, 13 females with ages, ranging from 47 to

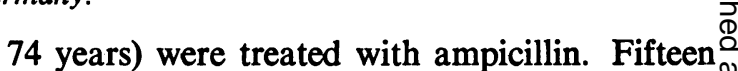
patients had an acute inflammatory process of ${ }^{\infty}$ the gallbladder, with varying degrees of $\vec{\circ}$ involvement of the adjacent bile passages; the other four patients had symptoms and signs ${ }_{\circ}^{\omega}$ of chronic biliary infection.

The diagnosis was established and the response to treatment was based on the following clinical symptoms and laboratory findings: severe abdominal pain, tenderness in right upper quadrant, palpable tumour of gallbladder, fever, leucocytosis, elevated ESR, bilirubinæmia and bilirubinuria, bile culture, etc.

Most cases of acute cholecytitis and/or cholangitis showed gallstones or a non functioning gallbladder on X-ray examination; one patient had a fistula between the gallbladder and $\mathcal{\Phi}_{\mathcal{O}}$ duodenum. One patient had already had ga 3 cholecystectomy, and another presented with@ an attack of acute cholangitis in association with biliary cirrhosis of the liver.

The four patients with chronic bilia disease showed milder clinical symptoms and signs but gave a history of epigastric fullness and pressure, nausea and heartburn aftero heavy meals and of recurrent slight jaundice; $\frac{\mathrm{O}}{\mathrm{D}}$ abnormal X-ray findings confirmed the diagno-

TABLE I

Concentrations of Ampicillin in Serum and Bile

\begin{tabular}{|c|c|c|c|c|c|c|}
\hline & $\begin{array}{l}\text { dose and route } \\
\text { of admin. }\end{array}$ & $\begin{array}{l}\text { hr. after } \\
\text { admin. }\end{array}$ & $\begin{array}{l}\text { conc. in } \\
\text { blood } \\
\mu \mathrm{g} . / \mathrm{ml} .\end{array}$ & $\begin{array}{l}\text { conc. in } \\
\text { bile } \\
\mu \mathrm{g} . / \mathrm{ml} .\end{array}$ & $\begin{array}{l}\text { ratio } \\
\text { bile } / \\
\text { serum }\end{array}$ & authors \\
\hline Rats & $100 \mathrm{mg} . / \mathrm{kg}$. oral & $\begin{array}{l}0-2 \\
2-4 \\
4-6\end{array}$ & $\begin{array}{l}0.25+ \\
0.41+ \\
0.19+\end{array}$ & $\begin{array}{l}65.9 \\
95.3 \\
83.7\end{array}$ & $\begin{array}{l}265 \\
231 \\
441\end{array}$ & $\begin{array}{l}\text { Acred } \\
\text { et al. }\end{array}$ \\
\hline Rats & 100 mg./kg. i.m. & $0.5-1.5$ & 16 & $1385-1344$ & $<85$ & $\begin{array}{c}\text { Harrison } \\
\text { and } \\
\text { Stewart }\end{array}$ \\
\hline \multirow[t]{2}{*}{ Rabbits } & \multirow[t]{2}{*}{$5.8 \mathrm{mg} . / \mathrm{kg}$. i.v. } & $\begin{array}{l}1 \\
2 \\
3\end{array}$ & $\begin{array}{l}2.7 \\
0.46 \\
0.43\end{array}$ & $\begin{array}{l}19.4 \\
22.05 \\
16.8\end{array}$ & $\begin{array}{l}7.2 \\
48 \\
39\end{array}$ & \multirow{2}{*}{$\begin{array}{l}\text { Auhagen } \\
\text { et al. }\end{array}$} \\
\hline & & $\begin{array}{l}1 \\
2 \\
3\end{array}$ & $\begin{array}{l}4.4 \\
1.0 \\
0.47\end{array}$ & $\begin{array}{l}18.5 \\
16.8 \\
36\end{array}$ & $\begin{array}{r}4.2 \\
16.8 \\
76.6\end{array}$ & \\
\hline Patient & $50 \mathrm{mg} . / \mathrm{kg}$. oral & $5-6$ & 10 & 22 & 2.2 & $\begin{array}{c}\text { Stewart } \\
\text { and } \\
\text { Harrison }\end{array}$ \\
\hline
\end{tabular}


TABLE II

Treatment of Biliary Infections with Ampicillin

Total number of patients

Acute cholecystitis and/or cholangitis

Chronic biliary infections

Good response to therapy

Therapy discontinued because of untoward reactions

Therapy with ampicillin ineffective
TABLE III

Symptoms and Findings in Acute Biliary Infections

number of patients before after

Severe abdominal pain

Tenderness in right upper quadrant

Gallbladder palpably distended

Fever (more than $38^{\circ} \mathrm{C}$.)

Leucocytosis

Elevated ESR

(more than $30 \mathrm{~mm} . / 1 \mathrm{hr}$ )

Bilirubinæmia

Pathogenic organisms in bile culture

Abnormal X-ray findings on cholecystography

\begin{tabular}{rr}
\multicolumn{2}{c}{ ampicillin } \\
14 & 3 \\
7 & 0 \\
4 & 0 \\
7 & 2 \\
9 & 1 \\
10 & 4 \\
6 & 1 \\
2 & 0 \\
13 & 13 \\
\hline
\end{tabular}

P. SCH., 51 YRS. M.

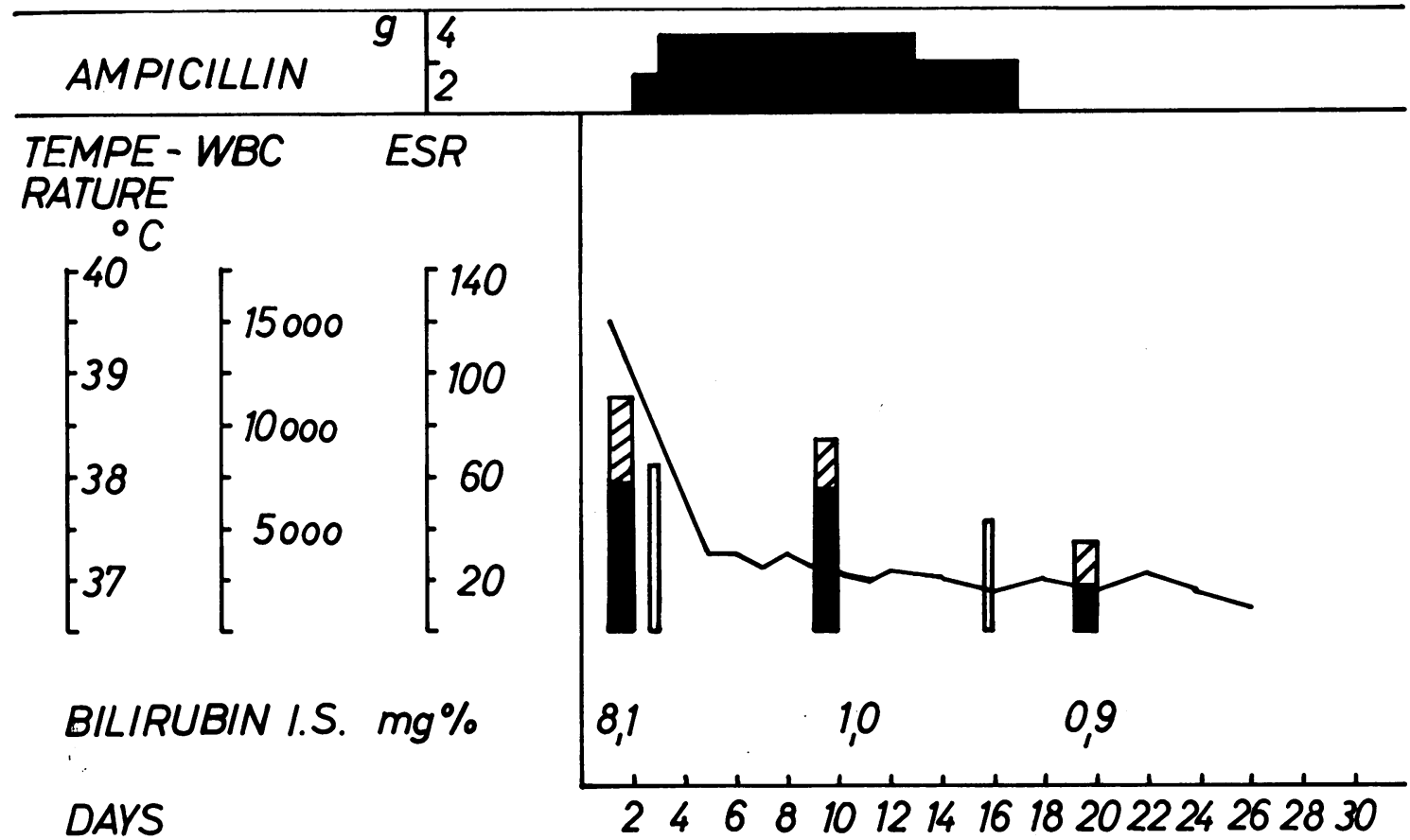

FIG. 1.-Effect of treatment with ampicillin in a 51 years old male with acute angiocholecystitis and obstructive jaundice.

sis (shrunken gallbladder with stones in one case, failure of gallbladder to fill in two cases, dilatation of common duct after cholecystectomy in one case).

All patients were treated with 2-3 g. ampicillin per day orally, given in four divided doses. The capsules were taken with some tea or water. The therapy was continued for 10-33 days (average 18 days) according to severity of illness.

Good response to ampicillin therapy was observed in 16 of the 19 cases with biliary infections. In two patients the therapy had to be stopped because of untoward reactions (gastrointestinal distress in one, grave headache in one). The remaining patient with acute 
M.L., 56 YRS. F.

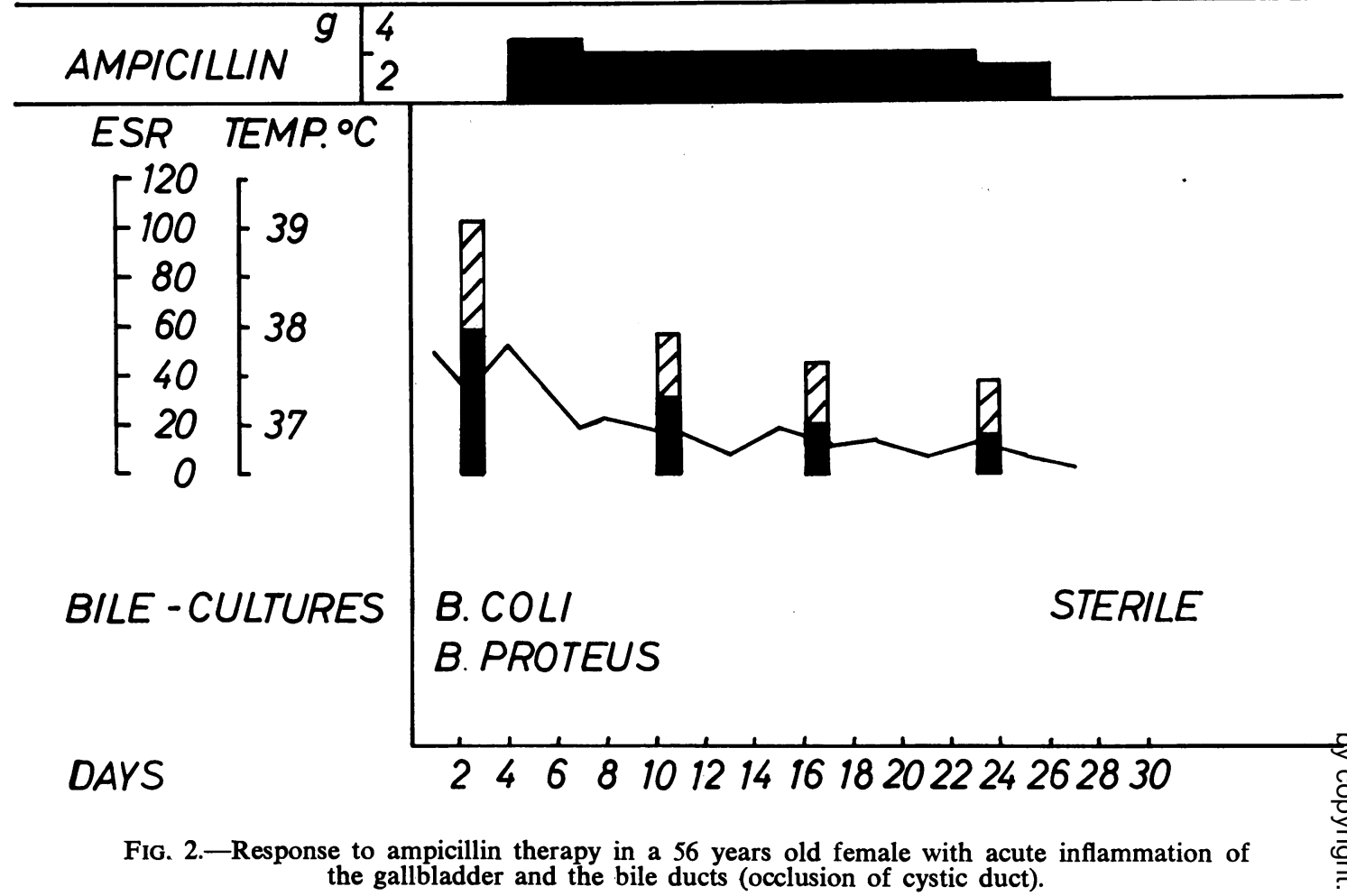

cholangitis and cirrhosis died in hepatic coma (Table II).

Symptoms and findings of patients with acute angio-cholecystitis before and after treatment with ampicillin are listed in Table III. It is remarkable that in these cases improvement usually began within the first two days of therapy and full recovery was seen after eight to ten days.

Figure 1 shows the effect of ampicillin therapy in a 51 years old male patient with acute angio-cholecystitis.

The clinical features on admission were severe pain, abdominal tenderness, high temperature, jaundice and elevated ESR. Under oral treatment with $3 \mathrm{gm}$. ampicillin daily and general supportive measures this patient recovered quickly; X-ray examination with "Biligrafin" revealed a wide common duct and negative cholecystography.

In Fig. 2 the clinical course of a 56 years old female patient with acute angio-cholecystitis is demonstrated.
On culture of the $\mathrm{A}$ and $\mathrm{C}$ fraction of the bile--aspirated from the duodenum $\frac{0}{\mathbb{O}}$ before therapy with ampicillin-Esch. coli and Proteus spp. were found and bile $\overrightarrow{\vec{B}}$ culture was sterile after three weeks of treat- $\exists$ ment. In this patient all symptoms and signs (colic, liver enlargement, slight jaundice, bilirubinuria and fever) subsided within one week of therapy. Two and a half months later a fibrotic gallbladder with thickened wall and a large stone in the cystic duct were removed at operation.

\section{Conclusion}

In conclusion we may say, that in treating을 our small series of patients with biliary infections ampicillin has proved to be a valuable drug. Similar good therapeutic results in these ${ }^{N}$ disorders were reported by other authors N (Germer, 1963; Meythaler and Ell, 1963;0 Mössner and Maurer, 1963). But the totate number of patients presented in medical literature ranges between 50 and 60 (our first nine $\stackrel{\infty}{+}$ cases included). 
One reason for these limited series is probably the fact, that until now we did not have an injectable preparation of ampicillin for clinical use. Therefore patients with severe nausea or vomiting in biliary infections had to be excluded from ampicillin therapy.

These preliminary results with oral therapy have been encouraging and at present we are carrying out further investigations using parenteral ampicillin to treat biliary infections.

\section{REFERENCES}

ACred, P., D. M. Braun, D. H. Turner, and
M. J. Wilson (1962): Brit. J. Pharmacol., 18, 356.

Auhagan, E., C. H. Gloxhuber, G. Hecht, T. H. KNOTT, H. OtTEN, E. RAuenbusCh, K. H. RisSe, J. Schmid, W. Scholtan, and A. M. Walter (1962): Arzneimittel-Forsch., 12, 791.

Germer, W. D. (1963): Arztl. Prax., 15, 573.

HARRISON, P. M., and STEWART, G. T. (1961): Brit. J. Pharmacol., 17, 420.

Meythaler, F., and Éll, O. (1963): Med. Klin., 58, 1265.

MöSSNER, G., and MAURER, H. (1963): Hippokrates (Stuttg.) 34, 654-661.

StewarT, G. T., and Harrison, P. M. (1961): Brit. J. Pharmacol., 17, 414.

ZylKA, W., M. CHRISTNER, and H. Moers (1962): Arzneimittel-Forsch., 12, 803.

\section{DISCUSSION}

LITTLER (Liverpool): I feel that acute cholecystitis is primarily a problem where the surgeon must be in at the beginning, because there are a certain number of these cases who are suitable for, and who should have, immediate cholecystectomy. They have to be carefully chosen, and I follow certain rules. It must be a first attack, and within the first 48 hours of the outset. The general medical condition of the patient should be suitable, and the patient must not be jaundiced. I personally do not accept the patient for immediate surgery if she is very fat-and we have in Liverpool a very large number of fat women with gallstones. Those for immediate cholecystectomy form only a small proportion of the cases with acute cholecystitis. The remainder are treated conservatively and $99 \%$ of them resolve. After they resolve, they are investigated and most of them later will be brought to cold surgery. The $1 \%$ which do not resolve, and do not improve clinically, require some operation, which is usually less than a cholecystectomy-drainage of a pericholecystic abscess, or the draining of the gall bladder itself and the removal of the stones.

In conservative treatment of these cases I use no antibiotic at all. I have used tetracycline and ampicillin, and I cannot honestly say that there is any difference at all in these groups. No two cases are strictly comparable, of course, and this is only a clinical impression.

I think the acutely inflamed gall bladder is, by and large, not functioning at that time; it may have been diseased for some time, there may have been stones for many years and it may be merely a fibrotic sac. But the admittedly high concentration of ampicillin in the bile is not an advantage in these cases, because the gall bladder which is acutely inflamed is not bathed in ampicillin, it is bathed in muco-pus, and as has already been said, there is probably a stone obstructing the cystic duct, or Hartmann's pouch, so that the bile is not in fact entering the gall bladder. It is reasonable to suppose that any antibiotic which is going tog have any good effect on that gall bladder must be taken there by the bloodstream, and notby the bile.

On the other hand, in acute ascending cholangitis, I think ampicillin may well have a place to play. This is a dangerous disease, not self-limiting and not amenable to surgery, and I am sure that any antibiotic which is present in the bile in high concentration will be well worth using in such a case.

GREENBERG (Massachusetts): One other point should be made along the lines of acute cholecystitis and also in terms of acute appendicitis, and acute pancreatitis; and that is, in the initial 24 to 48 hours, when you have leucocytosis and temperature elevation together with clinical signs and symptoms of acute cholecystitis, it does not necessarily imply that this has a bacterial basis. In cultures taken during laparotomy at this time, one frequently finds peritoneal fluid which is sterile, and this would suggest, therefore, that there is first a chemical peritonitis. As was just pointed out, many of these cases, with appropriate conservative therapy, can be managed so that an elective procedure can be done after an interval of time, when it is safer. 